\section{Taro (Colocasia esculenta) Transformed with a Wheat Oxalate Oxidase Gene for Improved Resistance to Taro Pathogen Phytophthora colocasiae}

\author{
Xiaoling $\mathbf{H e}^{1}$ \\ Hawaii Agriculture Research Center, P.O. Box 100, Kunia, HI 96759
}

Susan C. Miyasaka ${ }^{4}$

Department of Tropical Plant and Soil Sciences, University of Hawaii, 875 Komohana Street, Hilo, HI 96720

\author{
Maureen M.M. Fitch \\ Hawaii Agriculture Research Center, P.O. Box 100, Kunia, HI 96759
}

Sawsan Khuri

Center for Computational Science, University of Miami, Clinical Research Building, Miami, FL 33136

Yun J. Zhu ${ }^{3}$

Hawaii Agriculture Research Center, P.O. Box 100, Kunia, HI 96759

Additional index words. Agrobacterium tumefaciens, genetic engineering, transgenic, disease resistance, Taro leaf blight

\begin{abstract}
Production of taro [Colocasia esculenta (L.) Schott], a tropical root crop, is declining in many areas of the world as a result of the spread of diseases such as Taro leaf blight (TLB). Taro cv. Bun Long was transformed through Agrobacterium tumefaciens with the oxalate oxidase (OxO) gene $\boldsymbol{g} \mathbf{2} \mathbf{2 . 8}$ from wheat (Triticum aestivum). Insertion of this gene was confirmed by polymerase chain reaction (PCR) and Southern blot analysis. One independent transformed line contained one gene insertion (g5), whereas a second independent line contained four copies of the gene. Reverse transcriptase PCR (RT-PCR) confirmed the expression of this gene in line g5. Histochemical analysis of the enzyme oxalate oxidase confirmed its activity increased in the leaves of line g5. A bioassay for resistance to TLB used zoospores of Phytophthora colocasiae to inoculate tissue-cultured plantlets. Transgenic line g5 showed the complete arrest of this disease; in contrast, the pathogen killed non-transformed plants by 12 days after inoculation. A second bioassay, in which spores of $P$. colocasiae were inoculated onto disks of leaves of one-year-old potted plants, confirmed that transgenic line g5 had greatly increased resistance to this pathogen. This is the first report to demonstrate that genetic transformation of a crop species with an $\mathrm{OxO}$ gene could confer increased resistance to a pathogen (P. colocasiae) that does not secrete oxalic acid (OA).
\end{abstract}

Received for publication 4 Oct. 2012. Accepted for publication 7 Dec. 2012.

This project was supported by grants from the USDA-CSREES Tropical and Subtropical Agriculture Research (T-STAR) program.

The mention of a trademark, proprietary product, method, or vendor does not imply endorsement by the University of Hawaii, Hawaii Agriculture Research Center, China Academy of Tropical Agricultural Sciences, or the University of Miami nor its approval to the exclusion of other suitable products or vendors. We thank Dr. Francois Bernier at I.B.M.P. (Institut de Biologie Moleculaire Des Plants) in France for providing the plasmid pEMBL18:gf 2.8 .

${ }^{1}$ Formerly with the Department of Tropical Plant and Soil Sciences, University of Hawaii, 3190 Maile Way, Honolulu, HI 96822.

${ }^{2}$ Formerly with the School of Plant Sciences, University of Reading, Reading, U.K.

${ }^{3}$ Also with the Institute of Tropical Bioscience and Biotechnology, China Academy of Tropical Agricultural Sciences, Haikou, Hainan, P.R. China.

${ }^{4}$ To whom reprint requests should be addressed; e-mailmiyasaka@hawaii.edu.
Nakata, 2005; Palgi et al., 2005). In addition, insoluble calcium oxalate crystals could serve as herbivore feeding deterrents (Korth et al., 2006; Sakai et al., 1984). To reduce its toxicity, taro corms and leaves are well cooked before consumption by humans.

TLB, caused by the oomycete pathogen Phytophthora colocasiae, is a major disease that threatens the sustainability of taro worldwide. It reached the Hawaiian Islands during the 1920s and causes yield losses of up to $50 \%$ (Trujillo, 1967). During the 1990s, this disease spread to the Samoan Islands and resulted in $95 \%$ losses in traditional, TLB-susceptible taro cultivars (Brooks, 2000; Trujillo and Menezes, 1995). In 2004, it invaded the Dominican Republic, infecting 70\% to $95 \%$ of commercial taro plantings (J. Cho, personal communications, 2009).

OxO was first isolated and characterized from wheat (Triticum aestivum) (Lane et al., 1993). It catalyzes the oxidation of oxalic acid by molecular oxygen to form carbon dioxide and hydrogen peroxide $\left(\mathrm{H}_{2} \mathrm{O}_{2}\right)$. Researchers have found that increased $\mathrm{OxO}$ activity is associated with plant defense systems against a broad range of pathogens including viruses, bacteria, fungi, oomycetes, and nematodes (Dunwell et al., 2008). For example, Schweizer et al. (1999) found that transient expression of the pathogen-induced wheat germin $g f 2.8$ gene was associated with reduced penetration of the fungus Blumeria graminis.

There are several hypotheses to explain the mechanism of $\mathrm{OxO}$ in fungal resistance (Lane, 2002). First, $\mathrm{H}_{2} \mathrm{O}_{2}$ is generated by OxO-mediated breakdown of oxalate, resulting in hypersensitive cell death and antimicrobial activity (Peng and Kuc, 1992). Second, $\mathrm{H}_{2} \mathrm{O}_{2}$-mediated lignification of cell walls forms effective barriers against fungal penetration (Schweizer et al., 1999). Third, $\mathrm{H}_{2} \mathrm{O}_{2}$ generated by $\mathrm{OxO}$ could have a role in signal transduction cascades that coordinate various defense responses such as the synthesis of pathogenesis-related (PR) proteins and phytoalexins (Hammond-Kosack and Jones, 1996). Fourth, OA-generating fungi such as Sclerotinia sclerotiorum secrete high concentrations of $\mathrm{OA}$ as a toxin, and $\mathrm{OxO}$ is able to break down OA (Donaldson at al., 2001; Liang et al., 2001).

Genetic transformation with $\mathrm{OxO}$ genes has been reported in several plant species to improve resistance to pathogenic fungi that secrete OA (Donaldson at al., 2001; Dong et al., 2008). For example, Cober et al. (2003) found that a transgenic soybean line with an inserted wheat OxO gene $g f-2.8$ exhibited partial resistance to the white mold disease caused by S. sclerotiorum. Peanut (Arachis hypogaea) transformed with a barley oxalate oxidase gene showed enhanced resistance to Sclerotinia minor, the pathogen that causes Sclerotinia blight of peanut (Livingstone et al., 2005). Hybrid poplar (Populus $\times$ euramericana) transformed with a wheat $\mathrm{OxO}$ gene exhibited enhanced disease resistance against the fungus Septoria musiva (Liang et al., 2001). Because $\mathrm{OA}$ is a toxin secreted by these pathogenic 
fungi, it is not surprising that transgenic plants with an inserted $\mathrm{OxO}$ gene exhibited greater disease resistance.

In this study, we report on the Agrobacteriummediated transformation of taro cv. Bun Long with a wheat $\mathrm{OxO}$ gene, $g f 2.8$. Also, we demonstrated greatly enhanced resistance of transgenic taro plants to the oomycete Phytophthora colocasiae. This is the first OxO gene that exhibited greater resistance against an oomycete pathogen, $P$. colocasiae, that does not secrete OA.

\section{Materials and Methods}

Plant materials. Taro cv. Bun Long was chosen as the plant transformation material, because it is an important TLB-susceptible commercial cultivar in Hawaii. Earlier, we had developed an efficient regeneration and Agrobacterium-mediated transformation system for this cultivar (He, 2006; He et al., 2008).

Agrobacterium-mediated transformation. The plasmid pEMBL18:gf2.8 was provided by Dr. Francois Bernier at I.B.M.P. (Institut de Biologie Moleculaire des Plants) in France. Enzyme digestion followed by PCR analysis and partial sequencing verified that this plasmid contained the intact $2.8-\mathrm{kb} g f 2.8$ gene including its own promoter and terminator. The promoter for this gene is stimulated by both abiotic stresses (e.g., heavy metals, wounding, and plant growth regulators) and by biotic stresses (e.g., virus, fungus) (Berna and

The intact $2.8 \mathrm{~kb}$ OxO $g f 2.8$ gene fragment was extracted from the plasmid pEMBL18: $g f 2.8$ with the enzyme EcoRI and ligated into the EcoRI site of the vector pBI121 using standard methods (Sambrook and Russell, 2001). The plasmid pBI121:gf2.8 contained the $n p t \mathrm{II}$ selection gene, the gus reporter gene, and the intact $g f 2.8$ gene with promoter and terminator (Fig. 1). The plasmid pBI121: $g f 2.8$ was transformed into the Agrobacterium tumefaciens strain EHA105 using the freezing and thawing method described earlier by $\mathrm{He}$ et al. (2008). Agrobacterium-mediated transformation of taro $\mathrm{cv}$. Bun Long with the OxO $g f 2.8$ gene was conducted using the method of He et al. (2008).

Verification of presence of the OxO gene using polymerase chain reaction analysis. Genomic DNA was extracted from shoot tissues using the method described by $\mathrm{He}$ et al. (2008). The PCR primers specific for $g f 2.8$ were designed using Clone Manager softreport of a plant species transformed with an Bernier, 1999). ware (Cary, NC) and based on the $g f 2.8$ gene

sequence in GenBank (Lane et al., 1991). A pair of primers specific for amplifying the 755-bp fragment of the coding region of gf 2.8 was designed: gfF (20 mer) $5^{\prime}$-GCTTA GCAGCAGCAACAACC- $3^{\prime}$ and gfR (20 mer) 5'-GCGGCAAACTTGGACTTGAG-3' . The PCR analysis was conducted according to He et al. (2008).

Verification of expression of the OxO gene using reverse transcription-polymerase chain reaction analysis. Total RNA was isolated from fresh shoots and RT using the method described by He et al. (2008). As a control, PCR analysis was also conducted using total RNA without RT to confirm that the PCR product was derived from mRNA and not from the contaminating DNA. The plasmid pBI121:gf2.8 DNA was used as a positive control.

Southern blot analysis. Genomic DNA was extracted from shoot tissues using the sodium dodecyl sulfate method as modified by $\mathrm{He}$ et al. (2008). The DNA blotting, probing, and hybridization methods were described earlier by $\mathrm{He}$ et al. (2008).

Verification of $\mathrm{OxO}$ activity through the histochemical staining test. Leaves and shoots from one-year-old plants of the transformed g5 taro line or non-transformed cv. Bun Long were analyzed for $\mathrm{OxO}$ activity based on a histochemical assay (Dumas et al., 1995). Briefly, leaves and shoots were sliced and immersed in $10 \mathrm{mg} \cdot \mathrm{L}^{-1} 1$-naphthaleneacetic acid (NAA) solution for $2 \mathrm{~h}$ to induce gene expression because the promoter of $g f 2.8$ is induced by this hormone. Then, sliced leaves and shoots were placed in a solution containing oxalic acid $(2.5 \mathrm{mM})$ and 4-chloro1-naphthol $\left(0.6 \mathrm{~g} \cdot \mathrm{L}^{-1}\right)$ as the staining reagent. The incubation was conducted at $25^{\circ} \mathrm{C}$ in the dark for $24 \mathrm{~h}$. The OxO converts oxalic acid to $\mathrm{H}_{2} \mathrm{O}_{2}$ that endogenous peroxidases use to oxidize 4-chloro-1-naphthol, producing a dark blue precipitate (Dumas et al., 1995).

Bioassay of transgenic plants challenged by Phytophthora colocasiae. Six-month-old transgenic plantlets $(\approx 4 \mathrm{~cm}$ in height) of the transgenic line g5 or non-transformed plantlets were multiplied using tissue culture methods described in $\mathrm{He}$ et al. (2010). The line g5 was selected initially for all bioassays, because it contained a single transgene based on Southern analysis. In addition, propagated plantlets from this line appeared healthy and similar to non-transformed plantlets. Unfortunately, other transgenic lines were lost as a result of contamination after Southern analysis and could not be challenged with the pathogen.

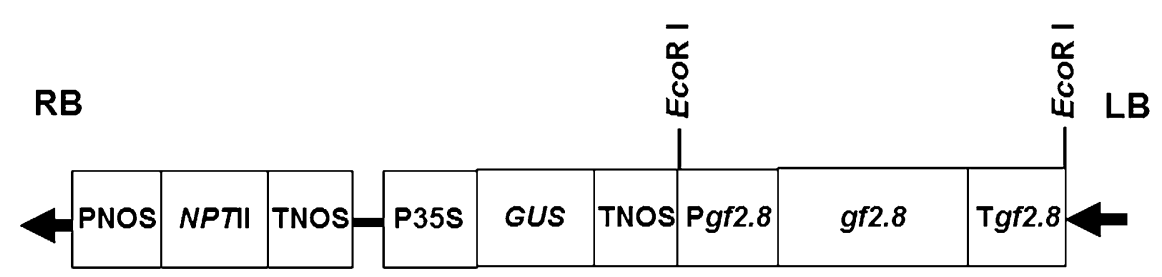

Fig. 1. Diagram of the transformation plasmid pBI121/gf 2.8 consisting of the $n p t I I$ selection gene, the gus reporter gene, and a wheat oxalate oxidase gene $g f 2.8$ driven by its own promoter.
Plantlets were inoculated with the oomycete pathogen $P$. colocasiae according to $\mathrm{He}$ et al. (2008). Briefly, a plug of V8 agar (Miller, $1955)$ bearing active spores $\left(\approx 0.2 \mathrm{~cm}^{3}\right)$ was placed spore side down on the cut shoot base of each plantlet. Each inoculated plantlet was placed on moistened filter paper and sealed in a petri dish to maintain $100 \%$ humidity. Three non-transformed plantlets and three transgenic plantlets of the line g5 were used in each trial, and each trial was repeated three times using a randomized complete block design. After inoculation, plantlets were observed daily for lesion initiation for $30 \mathrm{~d}$. At $12 \mathrm{~d}$, the lesion diameters were measured, averaged across three plantlets, and analyzed statistically by analysis of variance (ANOVA). The general linear model (GLM) program of SAS software (SAS Institute, Inc., Cary, NC) was used to conduct the ANOVA.

A second leaf-disk bioassay was performed with one-year-old potted plants, modifying the method of Brooks (2000). The youngest fully expanded mature leaves were selected from potted plants of one-year-old transgenic line g5 or non-transformed 'Bun Long' control plants. Leaf-disks $(20 \mathrm{~mm}$ in diameter) were excised with a cork borer. The leaf-disks were immediately placed in water agar plates. Twenty microliters of spore suspension $\left(1 \times 10^{4}\right.$ spores $\left./ \mathrm{mL}\right)$ were pipetted onto the center of each leaf-disk, and the plates were placed in a growth chamber maintained at $24{ }^{\circ} \mathrm{C}, 12 \mathrm{~h}$ light, and $100 \%$ relative humidity. Leaf-disks were observed daily and necrotic lesions were measured at $3 \mathrm{~d}$ after inoculation. Six leaf-disks from three individual plants of the g5 line and six leaf-disks from three individual plants of the non-transformed control were inoculated with the pathogen. Results of each leaf disk were averaged per treatment. Each experiment was repeated three times and data analyzed statistically by ANOVA using the GLM program of SAS software (Statistical Analysis System).

To compare the TLB resistance of the transgenic line g5 to naturally occurring TLBsusceptible and TLB-resistant cultivars, a third leaf-disk bioassay was performed using the Hawaiian commercial cultivar Maui Lehua (susceptible to TLB), the transgenic line g5, and three putative TLB-resistant cultivars, Pa'akala, BC99-6, and Ngesuas (P1). Cultivar Ngesuas was introduced from Palau based on observed field resistance to TLB; $\mathrm{cv}$. Pa'akala was bred conventionally by Trujillo for increased TLB resistance (Trujillo et al., 2002); and cv. BC99-6 was bred conventionally by Cho for greater TLB resistance Cho et al. (2007). The bioassay was conducted as described earlier, except for placing five leafdisks on each plate.

\section{Results}

Transformation of taro with the OxO gene. Using methods described earlier ( $\mathrm{He}, 2006$; He et al., 2008, 2010), calli were produced based on manipulation of plant hormones in tissue culture. In total, 200 pieces of calli $(\approx 2 \mathrm{~g})$ were transformed. Fifty calluses 
survived after $90 \mathrm{~d}$ of selection on $50 \mathrm{mg} \cdot \mathrm{L}^{-1}$ G418 and were transferred to the shootinducing medium containing the $50 \mathrm{mg} \cdot \mathrm{L}^{-1}$ G418 with subculturing every $30 \mathrm{~d}$. After $90 \mathrm{~d}, 30$ independent shoot lines were initiated on the selection media. After another $60 \mathrm{~d}$, only 10 lines survived the selection. PCR analysis was performed to screen transgenic lines. The expected 755-bp PCR product specific for the $g f 2.8$ gene fragment was found in eight lines (Fig. 2A), indicating that the $g f 2.8$ gene had been successfully transformed into these lines. No PCR product was obtained from the DNA extracted from nontransformed taro.

In addition, RNA was isolated from these eight lines and RT-PCR analysis conducted. The expected 755-bp RT product specific for the $g f 2.8$ gene fragment was found in all eight lines (Fig. 2B), indicating expression of the inserted gene. There was no RT product specific for the $g f 2.8$ gene fragment from RNA of non-transformed taro.

\section{A}

M P H g1 g2 g3 g4 g5 g6 g7 g8 NT
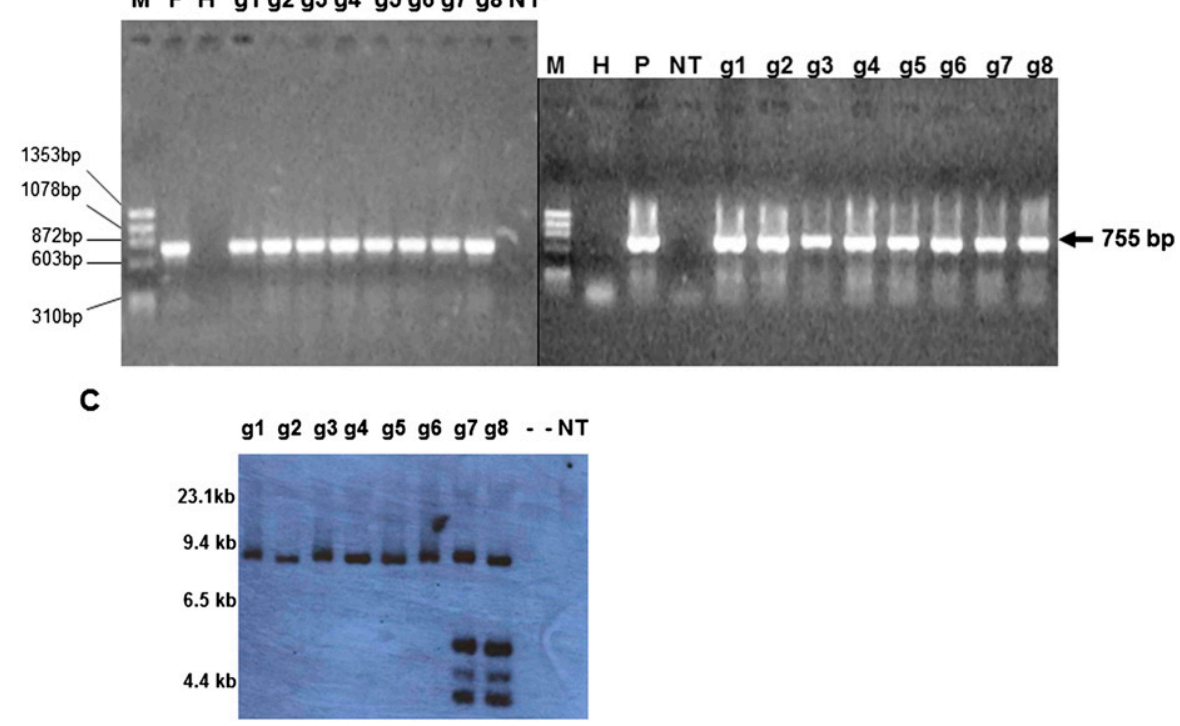

D

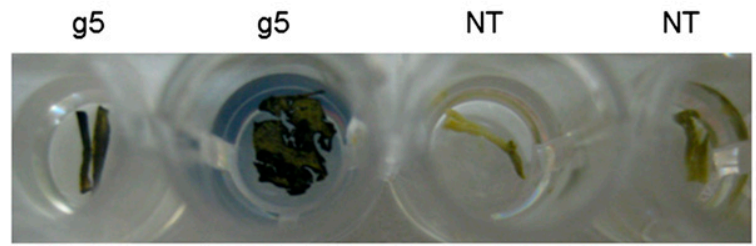

Fig. 2. (A) Polymerase chain reaction (PCR) analysis of taro cv. Bun Long lines transformed with EHA105:pBI121/gf2.8. M = molecular weight marker $\Phi$ X174/HaeIII; $\mathrm{P}=$ plasmid pBI121/gf2.8 control; $\mathrm{H}=$ water control; $\mathrm{g} 1-\mathrm{g} 8=$ transgenic lines $1-8 ; \mathrm{NT}=$ non-transformed plant control. (B) Reverse transcription-PCR analysis of taro lines transformed with EHA105:pBI121/gf2.8. M = molecular marker $\Phi$ X174/HaeIII; H = water control; $\mathrm{P}=$ plasmid $\mathrm{pBI} 121 / g f 2.8$ DNA control; NT = non-transformed plant control; g1-g8 = transgenic lines 1-8. The expected 755-bp PCR product specific for the gf 2.8 gene fragment was found in these eight transgenic lines, indicating both integration into genomic DNA and expression. (C) Southern blot analysis of eight lines (g1-g8) and a non-transformed control (NT). The enzyme BamHI cuts only once within the T-DNA region so that one band indicates one insertion of the transgene and four bands indicates four insertions of the transgene. (D) Histochemical assay of OxO activity in the transgenic line g5 (g5) or the non-transformed plantlet control (NT) after induction with NAA. Dark coloration indicates the presence of OxO activity in sliced g5 shoots (in Well 1, from left) and leaves (in Well 2, from left) that were incubated in 4-chloro-1-naphthol staining buffer with oxalic acid. Shoots (Well 3) and leaves (Well 4) of NT plantlets were unstained. $\mathrm{OxO}=$ oxalate oxidase; NAA $=1$-naphthaleneacetic acid.
Pathogenicity of the oomycete Phytophthora colocasiae. In a bioassay that inoculated tissue-cultured plantlets with $P$. colocasiae, chlorotic and necrotic, water-soaked lesions of non-transformed plantlets were visible at $3 \mathrm{~d}$ after inoculation, and these lesions increased in size over time until the plantlets were dead on the 12th day (Fig. 3A, left). In contrast, in each transgenic plantlet of line g5, small, reddish brown lesions occurred at the inoculation area within $3 \mathrm{~d}$ after inoculation, and they did not extend much further by $12 \mathrm{~d}$ after inoculation (Fig. 3A, right). All transgenic plantlets of the line g5 were alive and appeared healthy with green leaves and shoots even at $30 \mathrm{~d}$ after inoculation (Fig. 3A, right), indicating complete cessation of the movement of the pathogen $P$. colocasiae in transgenic plantlets of line g5. The lengths of lesions measured at $12 \mathrm{~d}$ after inoculation were significantly shorter $(P<0.05)$ in transgenic plantlets of line g5 with the wheat oxalate oxidase gene gf 2.8 compared with those of the non-transformed plantlets (Fig. 3B).

In a bioassay of one-year-old plants, inoculation of leaf disks from non-transformed taro with zoospores of $P$. colocasiae resulted in chlorotic and necrotic, water-soaked lesions within $24 \mathrm{~h}$ after inoculation. This lesion area increased over time, resulting in necrosis of the whole leaf disk of control plants within $3 \mathrm{~d}$ after inoculation (Fig. 3C, left). In contrast, leaf disks of transgenic line g5 did not exhibit water-soaked lesions within $24 \mathrm{~h}$ after inoculation, and only small lesions occurred at the inoculation area within $3 \mathrm{~d}$ after inoculation (Fig. 3C, right). The average lesion diameters measured at $3 \mathrm{~d}$ after inoculation were significantly smaller $(P<$ $0.05)$ in the transformed g5 line than in the non-transformed control (Figs. 3D).

In the third bioassay, necrotic lesions were observed on all leaf disks of susceptible cultivar Maui Lehua within $24 \mathrm{~h}$ after inoculation. This lesion area increased over time, resulting in necrosis of the whole leaf disk of cv. Maui Lehua within $3 \mathrm{~d}$ after inoculation (Figs. 3E, left). In contrast, much smaller lesions were evident on several leaf disks of TLB-resistant cultivar Pa'akala (Figs. 3E, middle) and all leaf disks of transgenic line g5 (Figs. 3E, right) within $24 \mathrm{~h}$ after inoculation. The white mycelium of $P$. colocasiae could be observed on several leaf disk surfaces of line g5, but there were either no lesions or only a few lesions of limited diameter that developed (Fig. 3E, right). Both cv. Pa'akala and transgenic line g5 showed significantly smaller lesions than cv. Maui Lehua, BC99-6, and P1 at $3 \mathrm{~d}$ after inoculation (Fig. 3E-F). There was no significant difference in average lesion diameter between transgenic line g5 and cv. Pa'akala (Figs. 3F).

\section{Discussion}

Transformation of taro with the $\mathrm{OxO}$ gene $g f 2.8$ from wheat showed great promise in controlling the major taro pathogen $P$. colocasiae, particularly in taro cultivars 
A
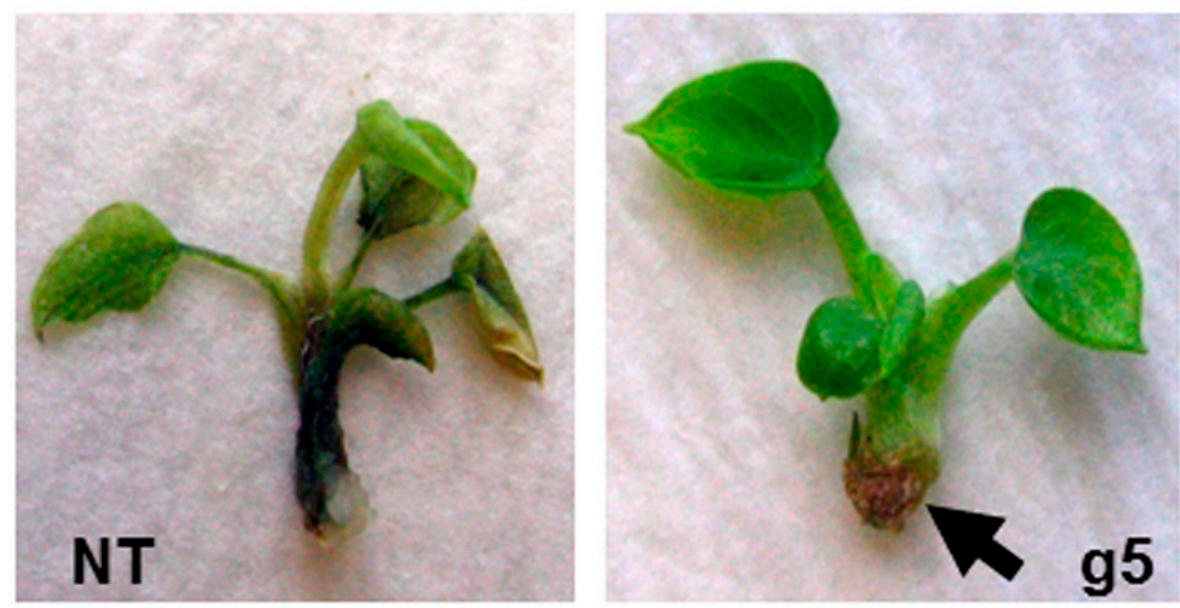

B

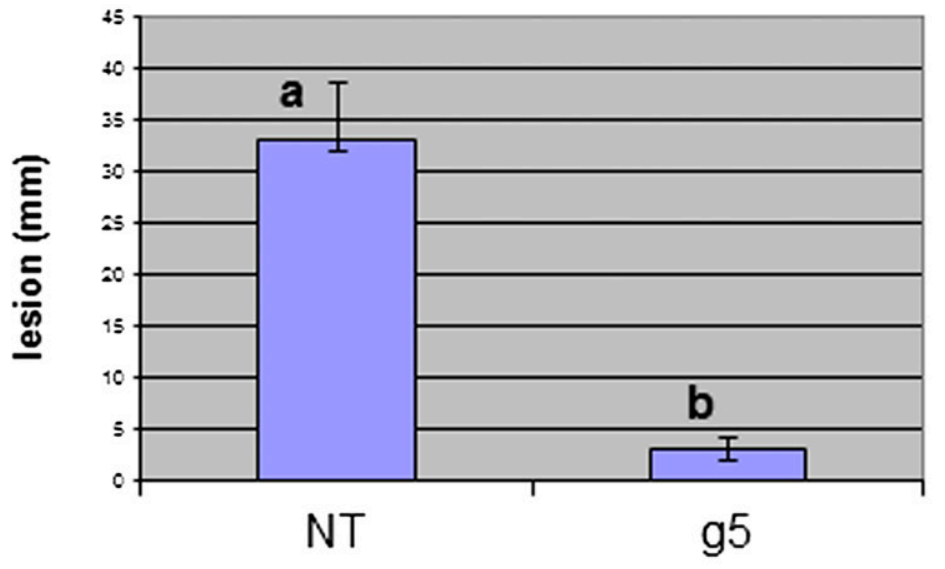

C

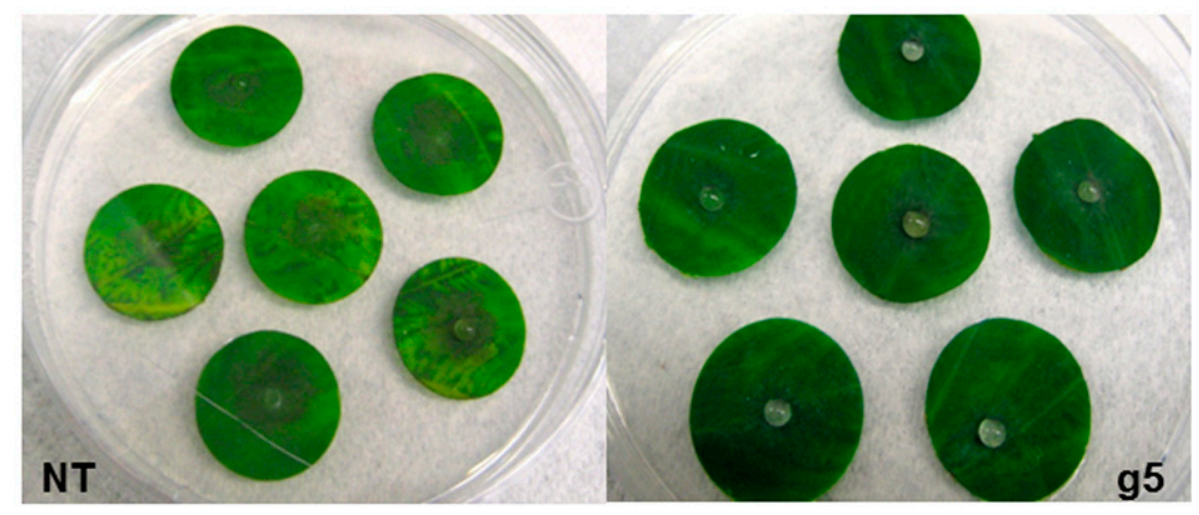

D

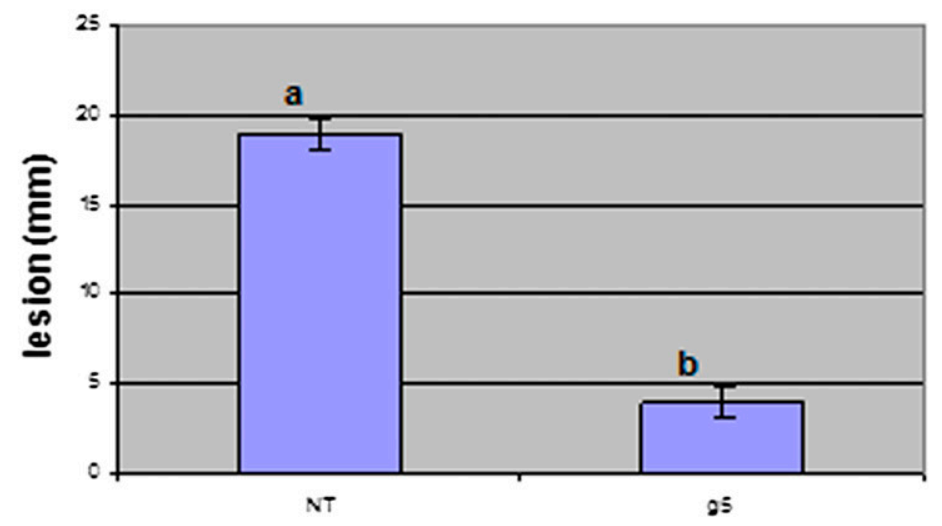

Fig. 3. Continued. 


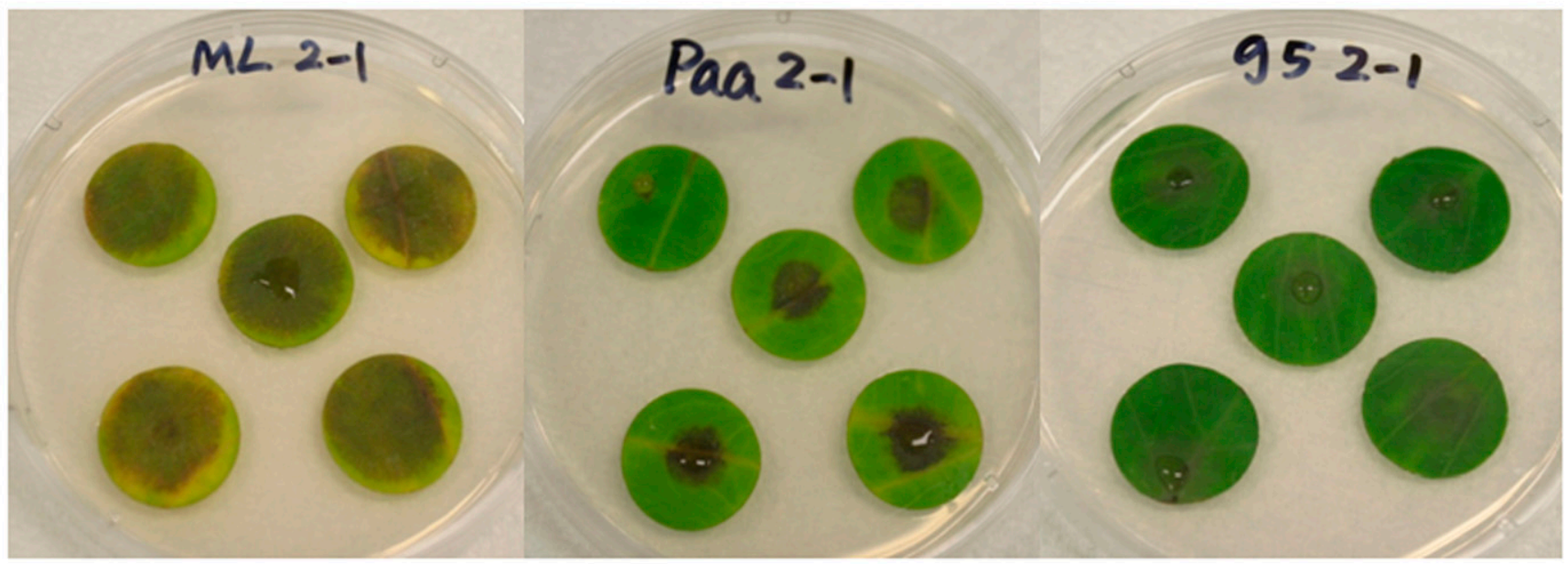

$\mathbf{F}$

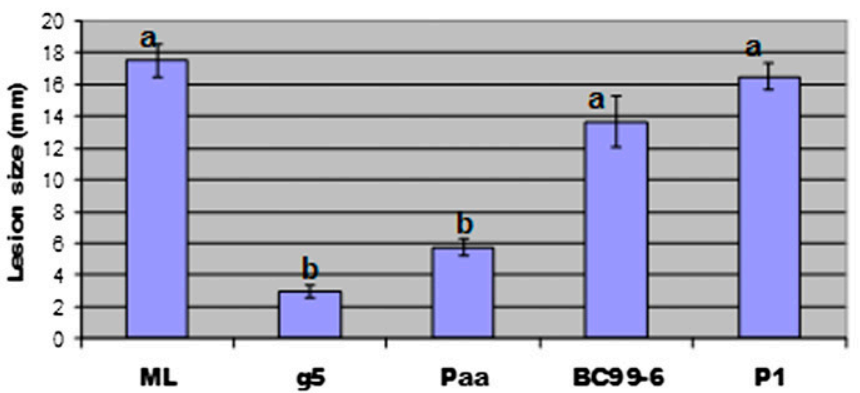

Fig. 3. (A) One plantlet of transgenic line g5 (g5, right) and one non-transformed plantlet control (NT, left) at $12 \mathrm{~d}$ after inoculation with P. colocasiae. The NT plantlet showed necrotic, water-soaked lesions extending from the cut shoot base to the leaf blades, and plants appeared dead. Plantlet of line g5 appeared green and healthy at $12 \mathrm{~d}$ and remained alive through $30 \mathrm{~d}$ when observations were ended. The arrow indicates where the agar disks containing spores were placed next to the cut shoot base. (B) Lesion length $(\mathrm{mm})$ of $P$. colocasiae-inoculated plantlets of non-transformed control (NT) or transgenic line g5 measured at $12 \mathrm{~d}$ after inoculation. Graph bars represent the mean \pm SD values of three replicates (each replicate consisted of three NT plantlets and three plantlets of g5). Different letters $(a, b)$ indicate significant differences $(P<0.05)$ using analysis of variance (ANOVA). (C) Leaf-disk bioassay of one-year-old potted plants of transgenic line g5 (g5, right) or non-transformed plantlet control (NT, left) challenged by $P$. colocasiae at $3 \mathrm{~d}$ after inoculation. Zoospore suspensions were pipetted onto the center of each leaf-disk and the lesion diameter measured at $3 \mathrm{~d}$ after inoculation. Note that the chlorotic and necrotic, water-soaked lesions expanded throughout the whole leaf disk of NT. In contrast, lesions expanded very little beyond the pipetted spore suspensions in leaf disks of line g5. (D) Lesion length $(\mathrm{mm})$ of $P$. colocasiae-inoculated leaf disks of non-transformed control (NT) or transgenic line g5 measured at $3 \mathrm{~d}$ after inoculation. Graph bars represent the mean \pm SD values of three replicates (each replicate consisted of the averages of six leaf disks in three plates). Different letters (a, $b)$ indicate significant differences $(P<0.05)$ using ANOVA. (E) Leaf-disk bioassay of transgenic line g5 (g5, right) and cvs. Maui Lehua (ML, left) and Pa'akala (Paa, middle) challenged by $P$. colocasiae at $3 \mathrm{~d}$ after inoculation. Zoospore suspensions were pipetted onto the center of each leaf-disk and the lesion diameter measured at $3 \mathrm{~d}$ after inoculation. Note that the chlorotic and necrotic, water-soaked lesions expanded throughout the whole leaf disk of ML. In contrast, lesions expanded to a much lesser extent in leaf disks of line g5 and cv. Paa. (F) Lesion length ( $\mathrm{mm})$ of $P$. colocasiae-inoculated leaf disks of commercial cv. Maui Lehua (ML), transgenic line g5, and putative TLB-resistant cvs. Pa'akala (Paa), BC99-6, and Ngesuas (P1) measured at $3 \mathrm{~d}$ after inoculation. Graph bars represent the mean \pm SD values of three replicates (each replicate consisted of averages of three plates $\times$ five leaf disks). Different letters (a, b) indicate significant differences $(P<0.05)$ using ANOVA. TLB $=$ Taro leaf blight.

that do not lend themselves to conventional cross-breeding. The spread of this oomycete pathogen was completely stopped in transgenic plantlets and greatly inhibited in leaf blades of one-year-old cv. Bun Long plants. To our knowledge, this is the first report of a transgenic plant with an inserted $\mathrm{OxO}$ gene that exhibited enhanced resistance to a pathogen ( $P$. colocasiae) that does not secrete OA. These results are of particular interest, because Taro leaf blight caused by $P$. colocasiae is one of the worst, most invasive diseases affecting the sustainability of taro production in the world.

This study provides evidence in support of either a direct effect of $\mathrm{H}_{2} \mathrm{O}_{2}$ (e.g., hypersensitive-like cell death or antimicrobial activity) or an indirect effect of $\mathrm{H}_{2} \mathrm{O}_{2}$ (e.g., cell wall lignification or induction of PR genes) on plant responses to pathogens. We have observed hypersensitive-like responses on transgenic line g5 plantlets (Fig. 3A, right); in addition, mycelium of $P$. colocasiae appeared to grow on the surface of the leaf disk but did not penetrate into the leaf tissue (Fig. 3C, right). Interestingly, Urs et al. (2006) reported that localized $\mathrm{H}_{2} \mathrm{O}_{2}$ levels and peroxidase activity increased when gametophytes of the fern Ceratopteris richardii were exposed to pathogen Pythium infestans, indicating that in this plant species, peroxidases may be involved in production of $\mathrm{H}_{2} \mathrm{O}_{2}$ and resistance to an oomycete pathogen.

One advantage of genetic transformation is that disease resistance gene(s) can be inserted into the genome of an elite cultivar, while maintaining all of its other desirable characteristics. Cultivar Bun Long is commercially important in Hawaii and the Dominican Republic; however, it flowers rarely under the environmental conditions found in these two islands. As a result of the difficulty in the induction of flowering of cv. Bun Long (even with the use of gibberellic acid that is effective on other taro cultivars), conventional breeding of this particular cultivar for increased disease resistance is extremely slow.

In contrast, commercially important cv. Maui Lehua is more amenable to conventional breeding, because it flowers naturally in Hawaii and in response to gibberellic acid. Although cv. Maui Lehua showed significantly less resistance to TLB than the transgenic line g5, its progeny, Pa'akala, exhibited similar resistance to the transgenic line g5. These results indicate that conventional breeding for increased TLB resistance is possible 
for elite cultivars that flower more readily such as cv. Maui Lehua.

Sharma et al. (2009) did not report upregulation of $\mathrm{OxO}$ genes in resistant taro cv. Muktakeshi compared with susceptible taro cv. UL-56 when each was infected by $P$. colocasiae. This result indicates that other PR proteins (e.g., chitinases) may be involved in TLB resistance of that particular taro cultivar. Interestingly, in previous research, taro transformed with the chitinase gene RICCHIII showed no change in resistance to the oomycete pathogen $P$. colocasiae (He et al., 2008, 2010).

Another advantage of genetic transformation to increase disease resistance is the ability to stack genes of interest (Sridevi et al., 2008). In previous research, transgenic taro with an inserted chitinase gene from rice showed moderately increased tolerance of the fungal pathogen Sclerotium rolfsii $(\mathrm{He}$ et al., 2008, 2010). Insertion of the OxO gene into taro also resulted in a modest increase in resistance to $S$. rolfsii (He, 2006). Perhaps, disease resistance could be enhanced further in future transgenic taro plants by the combined expression of a chitinase gene with the $\mathrm{OxO}$ gene as found in other plant species.

Despite the potential advantages of genetic transformation of taro with the OxO gene to confer enhanced disease resistance, such research in Hawaii has been suspended as a result of controversies discussed briefly by $\mathrm{He}$ et al. (2010). Research in our laboratory now focuses on identification of naturally occurring disease resistance genes in taro and marker-assisted selection to accelerate introgression of such genes into elite germplasm.

\section{Literature Cited}

Berna, A. and F. Bernier. 1999. Regulation by biotic and abiotic stress of a wheat germin gene encoding oxalate oxidase, a $\mathrm{H}_{2} \mathrm{O}_{2}$-producing enzyme. Plant Mol. Biol. 39:539-549.

Bohn, T., L. Davidsson, T. Walczyk, and R.F. Hurrell. 2004. Fractional magnesium absorption is significantly lower in human subjects from a meal served with an oxalate-rich vegetable, spinach, as compared with a meal served with kale, a vegetable with a low oxalate content. Br. J. Nutr. 91:601-606.

Brooks, F.E. 2000. Detached-leaf bioassay for evaluating taro resistance to Phytophthora colocasiae. Plant Dis. 92:126-131.

Cho, J.J., R.A. Yamakawa, and J. Hollyer. 2007. Hawaiian kalo, past and future. College Trop. Agr. \& Human Resources, Sustainable Agr., SA-1.

Cober, E.R., S. Rioux, I. Rajcan, P.A. Donaldson, and D.H. Simmonds. 2003. Partial resistance to white mold in a transgenic soybean line. Crop Sci. 43:92-95.
Donaldson, P.A., T. Anderson, B.G. Lane, A.L. Davidson, and D.H. Simmonds. 2001. Soybean plants expressing an active oligomeric oxalate oxidase from the wheat gf- 2.8 gene are resistant to the oxalate-secreting pathogen Sclerotinia sclerotiorum. Physiol. Mol. Plant Pathol. 59:297-307.

Dong, X., R. Ji, X. Guo, S.J. Foster, H. Chen, C. Dong, Y. Liu, Q. Hu, and S. Liu. 2008. Expressing a gene encoding wheat oxalate oxidase enhances resistance to Sclerotinia sclerotiorum in oilseed rape (Brassica napus). Planta 228:331-340.

Dumas, B., G. Freyssinet, and K. Pallett. 1995. Tissue-specific expression of germin-like oxalate oxidase during development and fungal infection of barley seedlings. Plant Physiol. 107:1091-1096.

Dunwell, J.M., J.G. Gibbings, T. Mahmood, and S.M.S. Naqvi. 2008. Germin and germin-like proteins: Evolution, structure, and function. Crit. Rev. Plant Sci. 27:342-375.

Food and Agriculture Organization of the United Nations. 2010. 12 Mar. 2012. <http://faostat. fao.org/>.

Franceschi, V.R. and P.A. Nakata. 2005. Calcium oxalate in plants: Formation and function. Annu. Rev. Plant Biol. 56:41-71.

Hammond-Kosack, K. and J. Jones. 1996. Resistance gene-dependent plant defense responses. Plant Cell 8:1773-1791.

$\mathrm{He}, \mathrm{X} .2006$. Transformation and regeneration of taro with two plant disease resistance genes: A rice chitinase gene and a wheat oxalate oxidase gene. $\mathrm{PhD}$ diss., University of Hawaii. ProQuest. UMI no. 3251049.

He, X., S.C. Miyasaka, M.M. Fitch, P. Moore, and Y.J. Zhu. 2008. Agrobacterium tumefaciensmediated transformation of taro (Colocasia esculenta (L.) Schott) with a rice chitinase gene for improved tolerance to a fungal pathogen Sclerotium rolfsii. Plant Cell Rpt. 27:903-909.

He, X., S.C. Miyasaka, Y. Zou, M.M. Fitch, and Y.J. Zhu. 2010. Regeneration and transformation of taro (Colocasia esculenta) with a rice chitinase gene enhances resistance to Sclerotium rolfsii. HortScience 45:1014-1020.

Korth, K.L., S.J. Doege, S.H. Park, F.L. Goggin, Q. Wang, S.K. Gomez, G. Liu, L. Jia, and P.A. Nakata. 2006. Medicago truncatula mutants demonstrate the role of plant calcium oxalate crystals as an effective defense against chewing insects. Plant Physiol. 141:188-195.

Lane, B.G. 2002. Oxalate, germins, and higherplant pathogens. IUBMB Life 53:67-75.

Lane, B.G., F. Bernier, K. Dratewka, R. Shafai, T.D. Kennedy, C. Pyne, J.R. Munro, T. Vaughan, D. Walters, and F. Altomare. 1991. Homologies between members of the germin gene family in hexaploid wheat and similarities between these wheat germins and certain Physarum spherulins. J. Biol. Chem. 266:10461-10469.

Lane, B.G., J.M. Dunwell, J.A. Ray, M.R. Schmitt, and A.C. Cuming. 1993. Germin, a protein marker of early plant development, is an oxalate oxidase. J. Biol. Chem. 268:12239-12242.

Liang, H.Y., C.A. Maynard, R.D. Allen, and W.A. Powell. 2001. Increased Septoria musiva resistance in transgenic hybrid poplar leaves expressing a wheat oxalate oxidase gene. Plant Mol. Biol. 45:619-629.

Livingstone, D.M., J.L. Hampton, P.M. Phipps, and E.A. Grabau. 2005. Enhancing resistance to Sclerotinia minor in peanut by expressing a barley oxalate oxidase gene. Plant Physiol. 137:1354-1362.

Miller, P.M. 1955. V-8 juice agar as a general purpose medium for fungi and bacteria. Phytopathology 45:461-462.

Palgi, N., I. Vatnick, and B. Pinshow. 2005. Oxalate, calcium and ash intake and excretion balances in fat sand rats (Psammomys obesus) feeding on two different diets. Comp. Biochem. Physiol. A Mol. Integr. Physiol. 141:48-53.

Peng, M. and J. Kuc. 1992. Peroxidase-generated hydrogen peroxide as a source of antifungal activity in vitro and on tobacco leaf disks. Phytopathology 82:696-699.

Plucknett, D.L., R.S. de la Pena, and F. Obrero. 1970. Taro (Colocasia esculenta), a review. Field Crops Abstracts 23:413-426.

Sakai, W.S., S.S. Shiroma, and M.A. Nagao. 1984. A study of raphide microstructure in relation to irritation. Scan. Electron Microsc. II:979-986.

Sambrook and Russell. 2001. Molecular cloning. A laboratory manual. 3rd Ed. Cold Spring Harbor Lab. Press, Cold Spring Harbor, NY.

Schweizer, P., A. Christoffel, and R. Dudler. 1999. Transient expression of members of the germinlike gene family in epidermal cells of wheat confers disease resistance. Plant J. 20:541-552.

Sefa-Dedeh, S., S. Agyir, and K. Emmanuel. 2004. Composition and the effect of processing on oxalate content of cocoyam Xanthosoma sagittifolium and Colocasia esculenta cormels. Food Chem. 85:479-488.

Sharma, K., A.K. Mishra, and R.S. Misra. 2009 Identification and characterization of differentially expressed genes in the resistance reaction in taro infected with Phytophthora colocasiae. Mol. Biol. Rpt. 36:1291-1297.

Sridevi, G., C. Parameswari, N. Sabapathi, V. Raghupathy, and K. Veluthambi. 2008. Combined expression of chitinase and $\beta$-1,3-glucanase genes in indica rice (Oryza sativa $\mathrm{L}$.) enhances resistance against Rhizoctonia solani. Plant Sci. 175:283-290

Trujillo, E.E. 1967. Diseases of the genus Colocasia in the Pacific area and their control. Proc. Intl. Symp. Trop. Root Crops 2:13-19.

Trujillo, E.E. and T. Menezes. 1995. Field resistance of Micronesian taros to Phytophthora blight. Phytopathology 85:1564.

Trujillo, E.E., T. Menezes, and C. Cavaletto. 2002. Promising new taro cultivars with resistance to taro leaf blight: 'Pa'lehua', 'Pa'akala', and 'Pauakea'. Univ. Hawaii College Trop. Agr. \& Human Resources, New plants for Hawaii, NPH-7.

Urs, R.R., P.D. Robert, and D.C. Schultz. 2006. Localisation of hydrogen peroxide and peroxidase in gametophytes of Ceratopteris richardii (C-fern) grown in the presence of pathogenic fungi in a gnotobiotic system. Ann. Appl. Biol. 149:327-336. 